\title{
Piloting an Oral History-Based CURE in a General Education Writing Course for First-Year Students
}

Joshua R. McConnell Parsons, University of Kentucky
Jannell C. McConnell Parsons, University of Kentucky
Kathryn Kohls, Jim Ridolfo, University of Kentucky

This public land-grant institution in Lexington, Kentucky, has a student population of approximately 30,000 , including 22,000 undergraduates. UK's demographic data shows 75 percent of undergraduates listed as white and 16.5 percent as underrepresented minority students (URM). Additionally, as of fall 2019, 26 percent of undergraduates identified as first-generation (FG) students (University of Kentucky 2020).

The course, WRD 110, is the first of a two-part sequence of required writing courses that all incoming students are required to take, usually in their first and second semesters at the institution. Assessment data were collected on course outcomes, with specific emphasis on student perceptions of their research skill acquisition and their confidence as researchers. Demographic data also were collected to examine the reach of the course and assess the course's impact on students more likely to miss out on undergraduate research experiences (UREs) if not given the opportunity in a general education class in their first year. In this article, a literature review on UREs and the reasons to implement CUREs in first-year courses more broadly is first undertaken. Then an overview of the course model and course outcomes is provided, and the specific assessment measures and findings are described. The goal of presenting these pilot data is to encourage more widely embedding CUREs in general education courses, specifically in humanities courses, to increase the access and equity of these experiences for first-year students.

\section{Literature Review}

The benefits of UREs are well-documented. Students who participate in UREs feel more prepared for careers (Craney et al. 2011; Lopatto 2003; Zhang, Raney, and Hatherill 
2018), have a higher likelihood of going to graduate school (Craney et al. 2011), and benefit from academic success credentials (e.g., publications and presentations) of participating in research (Lopatto 2003). Additionally, students report positive gains in knowledge, disciplinespecific skills (Bangera, Harrington, and Fuller 2018; Hayden 2015; Kuh 2008), and skills applicable across disciplines (Craney et al. 2011; Cuthbert, Arunachalam, and Licina 2012; Guertin and Clements 2018). Perhaps most important, students report growth in personal confidence (Bangera et al. 2018; Cuthbert et al. 2012), curiosity (Hensel 2018b; Lenhardt 2014; Maltese, Harsh, and Jung 2017), critical thinking (Allyn 2013; Hensel 2018b; Owens et al. 2018), and perseverance or "grit" (Hayden 2015; Lopatto 2003). For first-year students in particular, the benefits may be even greater. Outcome studies across first-year CUREs have shown promise in developing positive outcomes for students (Bangera et al. 2018; Guertin and Clements 2018; Zhang et al. 2018). Moreover, research has shown a positive link between firstyear URE participation and overall first-year satisfaction as well as a higher overall GPA at graduation (Bowman and Holmes 2018).

However, despite their clear potential for all the above benefits, UREs often do not reach a large portion of the student population. Various implementation choices and constraints often result in access barriers to a range of students (Hensel 2018b). For example, many UREs occur during the summer (Hensel 2018b), and if the URE is unfunded or underfunded this can limit access for low-income students who must work over the summers to support themselves. Additionally, UREs are frequently only available to third- and fourth-year students; however, retention data shows that the greatest attrition happens after the first year, particularly for FG and URM students (Radunzel 2018), meaning many students may never have the opportunity to participate. Moreover, UREs are often small, lab-based cocurricular activities that are the products of close relationships with faculty (Hensel 2018b). This model can limit access for a range of students, including low-income, working-class students who are less likely to seek out help, advice, or engagement activities (Calarco 2014; LongwellGrice and Longwell-Grice 2008) and therefore are less likely to engage in the relationship-building with faculty that is frequently a prerequisite for being asked to participate in small, lab-based research experiences. This model also may limit FG students who lack familial "college knowledge" that may help them actively seek out these types of opportunities (Ardoin 2018; Ardoin and martinez 2019). These access problems are particularly detrimental when seen in light of data showing that high-impact practices such as undergraduate research provide significantly greater academic benefits to URM and FG students who have historically been excluded from higher education (Kuh 2008; Pascarella et al. 2004).
Although the barriers to access are varied, one of the most impactful ways to mitigate many of these barriers and to increase access and equity is to make UREs more broadly available across the first-year general education course spectrum. To broaden the reach of UREs, institutions and faculty have turned to CUREs, which integrate research activities directly into the curriculum (Allyn 2013; Bangera et al. 2018; Hensel 2018b; Rowland et al. 2016), with some faculty integrating CUREs at the firstyear level. These first-year or early-career CUREs have been implemented across the disciplines, with several pedagogical examples highlighted in Hensel's Course-Based Undergraduate Research: Educational Equity and HighImpact Practice (2018a). Bangera and colleagues (2018), for example, have their first-year community college students learn genomic sequencing to create database entries for a national genomic database. Zhang and colleagues (2018) developed a similar model at a two-year Hispanicserving institution, where students sequence virus DNA for submission to a national database. In the humanities, Isbell (2018) has students in her introductory literature class construct annotated copies of public domain texts that include references and introductory explanatory articles, which are then utilized in introductory level courses in future years. Although the CUREs described in Hensel's publication provide several examples of early-career CURE implementations (2018a), the literature on specifically firstyear CUREs in general education classrooms is primarily geared toward first-year CUREs in STEM disciplines. The authors believe that there is a need to further expand the burgeoning conversation in the literature about what humanities CUREs in required first-year courses look like, given the importance of reaching as many first-year students as possible with these types of research experiences.

\section{The Course}

WRD 110 is part of the core curriculum at UK and the first of a two-part sequence of required research and writing courses taken by all undergraduate students. The learning objectives include a specific focus on inquiry-driven research and are standardized across all university sections of the course. A summary of these course objectives includes the following:

1. communicating in written and oral forms using inquirydriven research and writing methods and identifying different audience perspectives;

2. recognizing and using rhetorical strategies to communicate effectively;

3. gaining information literacy skills, including locating and analyzing primary and secondary data; and

4. working with others to improve writing skills and to increase engagement with issues under discussion.

Working within these course objectives, the pedagogical model presented here emphasizes the skills of inquiry 
and research as vital components of the composition and communication process by engaging students as actual researchers. In the initial pilot of this course, the instructor partnered with the on-campus Louie B. Nunn Center for Oral History, which has a large number of raw oral history interviews that require the development of a textual apparatus, or index, before the interviews can be placed in the center's searchable database. Students work in teams to create indices for previously unpublished oral histories using OHMS (Oral History Metadata Synchronizer) - a free, open-source, web-based application developed by the center (Louie B. Nunn Center for Oral History 2020). Students must make specific decisions about where to place bookmarks or chapters within the audio file and must determine appropriate titles for these chapters. In addition, students are responsible for tagging the interview with specific keywords that will assist researchers in finding the interview. As students engage in this process, they think critically about what the titles and keywords they create will imply to researchers and how their construction of the index will shape audience perceptions, engaging in a range of complicated and subjective rhetorical decisions. Beginning students receive classroom training in OHMS by the instructor and the Nunn Center. When finished, the indices and keywords are reviewed by the center and added to the database.

Next, students work in groups, as well as with various stakeholders, to develop multimodal digital stories using interviews that the group members have indexed. Students begin by proposing research questions and then work to contextualize the interviews and related research for a public audience. The digital story project requires primary research using the Nunn Center and special collections at UK Libraries as well as secondary research through the library databases. Although this course relies on a specific set of resources that are readily available on the UK campus, the work students do with these oral histories is not designed to make them into oral historians but rather to facilitate a CURE based on campus resources that (1) has real-world public audiences and impact, and (2) allows them to make the nuanced decisions that researchers regularly make about how to present primary research materials to those audiences.

\section{Measures}

First, the authors developed and utilized a logic model to determine specific course outcomes for assessment (see Figure 1). Outcomes chosen for assessment included the following:

1. student perceptions of knowledge creation,

2. student inquiry-based research skill acquisition,

3. student confidence as a researcher, and

4. student curiosity.
Researchers then utilized these outcomes to develop a retrospective precourse and postcourse assessment to gather data for this study. Research indicated that the retrospective precourse and postcourse assessment provided precourse and postcourse measures equally valid to traditional pre- and post-participation assessments (Howard 1980; Lam and Bengo 2003; Pratt, McGuigan, and Katzev 2000). Specific survey items related to students' perceptions of knowledge creation and confidence as researchers were developed based on logic model design and included a four-point Likert scale. A 13-item scale focused on inquiry-based research skills learned in the first-year writing classroom was developed and administered to students to assess skill acquisition. The scale was modified from the Undergraduate Research Student Self-Assessment (URSSA) tool utilized by NSFfunded Research Experiences for Undergraduates programs (University of Colorado Boulder n. d.). Researchers also explored students' level of curiosity via the 18-item Need for Cognition (NFC) scale (Cacioppo and Petty 1982) to evaluate students in comparison to other first-year cohorts. The NFC scale "measures how much people enjoy engaging in effortful cognitive activities" (Wabash College 2010, 48). In addition, demographic questions on race, gender, and FG status were asked to provide potential variables for use in the study. Because the concept of FG is not ubiquitous knowledge, students were given an explicit definition of the term $F G$ when asked the question.

\section{Procedures}

During fall 2018, two sections of the course were offered, resulting in a potential sampling frame of 46 students. Following Institutional Review Board approval, an online survey was distributed to students via student learning management software (Canvas) in December 2018, near the conclusion of the course. The survey included both post-participation and retrospective pre-participation questions. Students were asked first to rate their current skill level and then to rate their skill level prior to the course. Students could not view their responses to the prior question matrices. Students were offered an incentive of 10 extra credit points if they completed the survey and were given the option to opt out of research while still earning extra credit.

\section{Data Analysis}

Collected data yielded a total of 45 responses from the two course sections. Data were cleaned to remove incomplete responses, duplicated responses, and responses from students who opted out of research. Thirty-one responses remained following this phase. Demographic data were analyzed for descriptive statistics using Excel. Data were then analyzed using statistical software (SPSS). Retrospective precourse data were compared to post-course data for change over time utilizing paired sample $t$-tests for scaled 
FIGURE 1. Logic Model Developed Prior to Implementation of Fall 2018 Course

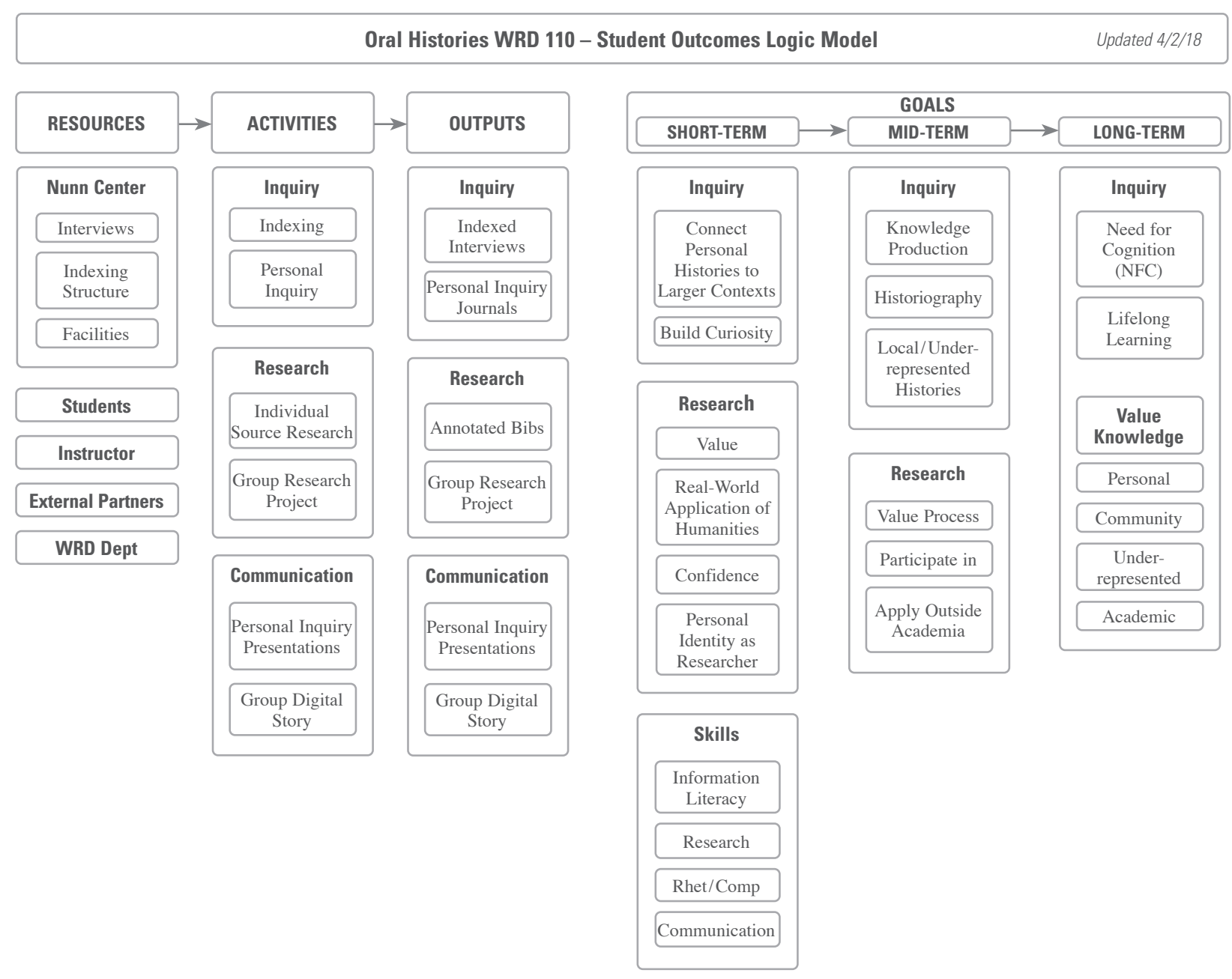

items (skill items) and the Wilcoxon signed-rank test for individual items that did not show normal distribution.

\section{Results}

\section{Participants}

A total of 31 students provided data for the study. Twentyfour students participating in the study selected female, and seven selected male. Most participants were white $(n=26$, 84 percent). Approximately one-third of students were FG students ( $n=10,32$ percent). When compared to the demographic breakdown of undergraduates at the institution, female students were overrepresented (77 percent of the sample compared to 56 percent of the institution). White students also were overrepresented ( 84 percent of the sample compared to 75 percent of the institution). Additionally, institutional data indicated that approximately 17 percent of fall 2018 undergraduates were classified as FG. Finally, students' NFC was examined to determine whether students were similar to other first-year students. Median NFC for the sample was 3.33 out of 5 with a standard deviation of 0.63 . Benchmarked data from the
University of Rhode Island's "Findings from the First Year of the Wabash National Study 2008-2009" (Wabash College 2010) indicated that the NFC across 52 institutions of all sizes was approximately 3.45 with a standard deviation of 0.61. Based on this data, the sample respondents fell within a standard deviation (SD) of a nationally normed data sample.

\section{Student Confidence}

Students reported generally positive gains in confidence related to considering themselves researchers and their ability to complete future research projects. Agreement with the statement "I feel prepared to complete future college-level research projects" rose by approximately 35 percent. Statistical analysis indicated that this was a statistically significant change $(Z=-2.702, p=0.007)$ with a precourse median score of 2.55 (SD 0.768) and a post-course median score of 3.03 (SD 0.657). Similarly, agreement with the statement "I consider myself a researcher" rose approximately 39 percent from precourse to postcourse $-\mathrm{a}$ significant change $(Z=-3.337, p=$ 0.001 ). The precourse median score was 2.32 (SD 0.909), 
and the postcourse median score was 2.97 (SD 0.795). However, students of the program saw little change in their interest in seeking out additional research opportunities in college. A total of 20 students reported an intention of seeking out research opportunities before entering the class and this number only increased to 22 by the end of the course. In addition, students retrospectively reported high agreement with the statement "student researchers can create new knowledge," with 25 of 31 (80.6 percent) agreeing with the statement. Upon completing the course, 30 of 31 students agreed with the statement.

\section{Perceived Skill Gains}

Students reported gains across the board in research skills. Students were asked to assess their research skills on a four-point scale with the response options "no skill," "minimal skill," "average skill," and "advanced skill." For the purposes of analysis, "average skill" and "advanced skill" were aggregated to allow researchers to assess the total number of students who felt they were capable in the skill area. Areas that saw the highest increase of students reporting advanced or average skill included locating and using peer-reviewed secondary research for research-based projects and using the library system to locate research. Of all statements related to skill acquisition, the least number of students on the postsurvey questions reported average or advanced skills in "communicating research to a public audience." Table 1 provides a full list of skill items and students' reported precourse and postcourse agreement with statements.

These 13 items also were analyzed as a scale to assess improvement in overall inquiry-based research skill acquisition. Cronbach's alpha test showed high internal validity (alpha $=0.900$ for postcourse and 0.963 for precourse results), indicating that the items could be treated as a scale. Statistical analysis of students' retrospective precourse perceptions of skill levels $(\mathrm{M}=34.29, \mathrm{SD}=9.58)$ compared to students' postcourse perceptions of skill levels $(M=41.68, S D=4.812)$ showed a significant difference from precourse to postcourse on the following scale: $t(30)=4.569, p<0.001$.

\section{URM and FG Students}

The number of students reporting underrepresented racial or ethnic minority status was too low to analyze; however,

TABLE 1. Comparison of Student-Perceived Skill Levels from (Retrospective) Precourse to Postcourse

\begin{tabular}{|c|c|c|c|c|c|c|}
\hline \multirow{2}{*}{ Skill items } & \multicolumn{2}{|c|}{$\begin{array}{c}\text { Precourse } \\
\text { Avg. or Adv. Skills }\end{array}$} & \multicolumn{2}{|c|}{$\begin{array}{l}\text { Postcourse } \\
\text { Avg. or Adv. Skills }\end{array}$} & \multicolumn{2}{|c|}{ Growth } \\
\hline & $n$ & $\%$ & $n$ & $\%$ & $n$ & $\%$ \\
\hline $\begin{array}{l}\text { Locating peer-reviewed secondary research for } \\
\text { research-based projects }\end{array}$ & 16 & $51.61 \%$ & 30 & $96.77 \%$ & 14 & $45.16 \%$ \\
\hline $\begin{array}{l}\text { Using peer-reviewed secondary research for } \\
\text { research-based projects }\end{array}$ & 17 & $54.84 \%$ & 31 & $100.00 \%$ & 14 & $45.16 \%$ \\
\hline Using library system to locate research sources & 15 & $48.39 \%$ & 29 & $93.55 \%$ & 14 & $45.16 \%$ \\
\hline Using primary sources in research-based projects & 18 & $58.06 \%$ & 31 & $100.00 \%$ & 13 & $41.94 \%$ \\
\hline $\begin{array}{l}\text { Summarizing source materials for a research } \\
\text { audience }\end{array}$ & 19 & $61.29 \%$ & 31 & $100.00 \%$ & 12 & $38.71 \%$ \\
\hline Locating primary sources for research-based projects & 17 & $54.84 \%$ & 28 & $90.32 \%$ & 11 & $35.48 \%$ \\
\hline Assessing the credibility of a source & 17 & $54.84 \%$ & 27 & $87.10 \%$ & 10 & $32.26 \%$ \\
\hline Adjusting writing for different audiences & 20 & $64.52 \%$ & 30 & $96.77 \%$ & 10 & $32.26 \%$ \\
\hline Writing for a research audience & 19 & $61.29 \%$ & 29 & $93.55 \%$ & 10 & $32.26 \%$ \\
\hline Collaborating with others on research-based projects & 22 & $70.97 \%$ & 31 & $100.00 \%$ & 9 & $29.03 \%$ \\
\hline $\begin{array}{l}\text { Articulating the importance of research to a public } \\
\text { audience }\end{array}$ & 19 & $61.29 \%$ & 28 & $90.32 \%$ & 9 & $29.03 \%$ \\
\hline Communicating research to a public audience & 18 & $58.06 \%$ & 26 & $83.87 \%$ & 8 & $25.81 \%$ \\
\hline Talking about research interests with peers & 23 & $74.19 \%$ & 28 & $90.32 \%$ & 5 & $16.13 \%$ \\
\hline Average & 18 & $59.55 \%$ & 29 & $94.04 \%$ & 11 & $34.49 \%$ \\
\hline
\end{tabular}

Note: $n=31$. The table above shows a comparison of student responses (aggregating "average skill" and "advanced skill") to each skill-related question, (retrospectively) precourse and postcourse. 
although there were not enough data for statistical significance, students self-identifying as FG students $(n=10)$ demonstrated particularly high gains in some areas. On the precourse assessment, three FG students reported agreement with the question about being prepared for future college-level research projects. Postcourse, however, all 10 FG students felt prepared for future college-level research projects. For the statement "I consider myself a researcher," nine FG students agreed with the statement postcourse, compared to four who agreed with the same question when asked to rate their precourse opinions retrospectively. FG students saw comparatively higher gains in terms of skill acquisition as well. For all skill questions except "talking about my research interests with my peers," which showed high precourse agreement in both groups, the average growth for the non-FG student cohort across all skill-related questions was approximately 35 percent. For FG students, the aggregated growth for the cohort was approximately 39 percent. Reported precourse skill levels for both cohorts were approximately the same (59 percent of students in both groups reported average or advanced skills).

\section{Discussion}

This study builds on an emerging literature base that provides a blueprint for ways to integrate UREs into the first year. Like colleagues' courses in the sciences (Bangera et al. 2018; Zhang et al. 2018), this course relies heavily on database building to provide students with an opportunity to contribute meaningful work to the academic community. Moreover, this model leverages similar pedagogical practices to those seen in other humanities CUREs (Isbell 2018) by asking students to wrestle with the implications associated with the presentation of data during the database development phase and the public presentation of findings through the digital story.

Data suggest that the course model in this study provided students with an experience that equipped them with the skills and confidence necessary to continue on to future advanced college-level research projects. Although the exploratory nature of this study does not allow for the generalization of these findings, student-reported increases in skills and confidence match reported gains in the URE literature. Similarly, the reported gains for FG students build on prior literature that shows the value of high-impact practices for FG students (Pascarella et al. 2004). Moreover, the percentage of FG students in the course was higher $(n=$ 10,32 percent) than the average percentage at the institution in fall 2018 (17 percent). Although the sample size in this pilot is too small to make significant claims, this difference may add further evidence to Hensel's claims that early integration of CUREs into the curriculum increases access and equity for underrepresented students (2018b).

Arguably the most intriguing aspects of this oral history-based CURE are the potential for adaptability across disciplines, transferability to other institutions, and scalability. Oral history archives offer valuable primary sources on a wide range of topics that cross disciplinary boundaries. This topical diversity may make this model attractive to practitioners designing a range of general education courses that focus on teaching inquiry-based research skills. Constructing oral history indices offers students the ability to engage deeply with primary source content while also developing critical research and writing skills. In addition, given the open nature of the oral history software, this particular model could be implemented at any institution with reliable internet access. Because the application utilized for indexing, OHMS, is free and open source, it can be used by anyone and in fact is "currently used by 100 archives in 18 different countries" (University of Kentucky n. d.). Faculty could likely find willing partners to provide raw materials for indexing if interested in the model. Several examples of partnerships using OHMS are available in the literature (Boyd, Fernheimer, and Dixon 2015; Fernheimer et al. 2018; Royles 2016; Smucker, Boyd, and Hardy 2017). Finally, the minimal resources required to implement this course give the model potential for scalability if appropriate partnerships and support systems are in place. Nearly all components needed for implementation are freely available (OHMS, the oral history interviews, basic webpage development software), making the only major hurdles to implementation in multiple classrooms the availability of enough raw data and the time investment required by faculty.

Although these pilot data do suggest some positive outcomes, there are limitations to this study. Without benchmark or comparative data, it is difficult to assess whether student gains were the result of normal first-year student growth or the product of this intervention. From a firstyear instruction perspective, student preparation and prior knowledge can vary, requiring instructors to adapt and scaffold teaching to meet the particular needs of this variable student population. Similarly, as with any student-led project that results in a public-facing product, faculty members and other personnel must invest additional time and energy in ensuring student work meets the standards of submission. From an implementation and sustainability perspective, the raw oral history interviews students work with must undergo some form of curation at the outset to ensure consistency. Additionally, the collaborative nature of this initiative requires a sustained relationship between the instructor and the oral history center. Scaling of this model potentially also may create a backlog of data to be checked for accuracy before entry into the database. Finally, it should be noted that designing and teaching this type of CURE often requires time and resources not easily accessible to the contingent faculty who increasingly teach general education courses. By utilizing resources freely and readily available on campus (Nunn Center interviews and OHMS) and partnering closely with on-campus 
stakeholders (the Nunn Center and UK librarians), some of these challenges were mitigated for this particular project. Local institutional contexts greatly affect the possibilities for general education instructors to implement CUREs in first-year classrooms. Implementation challenges should be explored in future studies.

Despite these limitations, findings suggest this model has the potential to promote student learning while providing an equitable and accessible high-impact experience in the first year. Based on this initial success, the course was implemented on a wider scale in fall 2019 and fall 2020 , including approximately 15 sections each year. For this scaled-up implementation, another pedagogical model implemented in the same course (WRD 110) will be used as a comparison. To date, fall 2019 data have been collected, but only preliminary data analysis has been performed. Fall 2020 data collection is ongoing. Based on lessons learned in this pilot, future analysis will continue to focus on exploring both student learning outcomes and scalability issues. Student voice data from student written assignments, including weekly journals, also are being collected for analysis. Beyond this next phase of implementation, research should explore how scaling is implemented for best practices in integration of oral history-indexing CUREs into first-year general education classrooms more broadly.

All students deserve access to high-impact educational practices like undergraduate research. Yet the self-selecting nature of many UREs limit their reach, and students who are more likely to leave college after the first year may never access these experiences. As Nancy Hensel states in her call to action, "incorporating research into general education courses may be the most effective way to ensure that every student has the opportunity to engage in undergraduate research and reap its benefits" (2018b, 9). The model developed and analyzed in this study demonstrates the viability of integrating CUREs directly into humanities-based general education classrooms for firstyear students.

\section{References}

Allyn, Debra A. 2013. "Course-Based Undergraduate Research: It Can Be Accomplished!" Journal of Physical Education, Recreation \& Dance 84(9):32-36. doi: 10.1080/07303084.2013.838113

Ardoin, Sonja. 2018. "Helping Poor- and Working-Class Students Create Their Own Sense of Belonging." New Directions for Student Services 162: 75-86. doi: 10.1002/ss.20263

Ardoin, Sonja, and becky martinez. 2019. Straddling Class in the Academy: 26 Stories of Students, Administrators, and Faculty from Poor and Working-Class Backgrounds and Their Compelling Lessons for Higher Education Policy and Practice. Sterling, VA: Stylus.

Bangera, M. Gita, Kim Harrington, and Jason Fuller. 2018. "COMGEN: Developing the Pedagogy for Classroom-Based
Undergraduate Research Experience Courses.” In Hensel 2018a, $13-24$.

Bowman, Nicholas A., and Joshua M. Holmes. 2018. "Getting Off to a Good Start? First-Year Undergraduate Research Experiences and Student Outcomes." Higher Education 76: 17-33. doi: 10.1007/s10734-017-0191-4

Boyd, Douglas A., Janice W. Fernheimer, and Rachel Dixon. 2015. "Indexing as Engaging Oral History Research: Using OHMS to 'Compose History' in the Writing Classroom." Oral History Review 42: 352-367.

Cacioppo, John T., and Richard E. Petty. 1982. "The Need for Cognition." Journal of Personality and Social Psychology 42: 116-131. doi: 10.1037/0022-3514.42.1.116

Calarco, Jessica McCrory. 2014. "Coached for the Classroom: Parents' Cultural Transmission and Children's Reproduction of Educational Inequalities." American Sociological Review 79: 1015-1037. doi: 10.1177/0003122414546931

Craney, Chris, Tara McKay, April Mazzeo, Janet Morris, Cheryl Prigodich, and Robert de Groot. 2011. "Cross-Discipline Perceptions of the Undergraduate Research Experience." Journal of Higher Education 82: 92-113. doi: 10.1080/00221546.2011.11779086

Cuthbert, Denise, Dharma Arunachalam, and Dunja Licina. 2012. "It Feels More Important Than Other Classes I Have Done': An 'Authentic' Undergraduate Research Experience in Sociology." Studies in Higher Education 37: 129-142. doi: 10.1080/03075079.2010.538473

Fernheimer, Janice W., Douglas A. Boyd, Beth L. Goldstein, and Sarah Dorpinghaus. 2018. "Sustainable Stewardship: A Collaborative Model for Engaged Oral History Pedagogy, Community Partnership, and Archival Growth." Oral History Review 45: 311-331.

Guertin, Laura, and Nina Clements. 2018. "Starting the Research Process with Information Literacy in Introductory-Level Earth Science Courses.” In Hensel 2018a, 25-34.

Hayden, Wendy. 2015. “'Gifts' of the Archives: A Pedagogy for Undergraduate Research." College Composition and Communication 66: 402-426.

Hensel, Nancy H. (Ed.). 2018a. Course-Based Undergraduate Research: Educational Equity and High-Impact Practice. Sterling, VA: Stylus.

Hensel, Nancy H. 2018b. "Crazy Observations, Audacious Questions.” In Hensel 2018a, 1-11.

Howard, George. 1980. "Response-Shift Bias: A Problem in Evaluating Interventions with Pre/Post Self-Reports." Evaluation Review 4: 93-106. doi: 10.1177/0193841X8000400105

Isbell, Mary. 2018. "Editing the Public Domain with Undergraduates.” In Hensel 2018a, 35-45.

Kuh, George D. 2008. High-Impact Educational Practices: What They Are, Who Has Access to Them, and Why They Matter. Washington, DC: Association of American Colleges and Universities.

Lam, Tony C. M., and Priscilla Bengo. 2003. "A Comparison of Three Retrospective Self-Reporting Methods of Measuring 
Change in Instructional Practice." American Journal of Evaluation 24: 65-80. doi: 10.1177/109821400302400106

Lenhardt, Allison K. 2014. "Digital Literacy and Undergraduate Humanities Research." CEA Critic 76: 336-342. doi: 10.1353/ cea.2014.0037

Longwell-Grice, Rob, and Hope Longwell-Grice. 2008. "Testing Tinto: How Do Retention Theories Work for FG, Working-Class Students?" Journal of College Student Retention: Research, Theory \& Practice 9: 407-420. doi: 10.2190/CS.9.4.a

Lopatto, David. 2003. "The Essential Features of Undergraduate Research.” CUR Quarterly 23(3): 139-142.

Louie B. Nunn Center for Oral History. 2020. "OHMS: Oral History Metadata Synchronizer." University of Kentucky Libraries. https://www.oralhistoryonline.org

Maltese, Adam, Joseph Harsh, and Eunju Jung. 2017. "Evaluating Undergraduate Research Experiences: Development of a Self-Report Tool." Education Sciences 7(4): 87. doi: 10.3390/ educsci7040087

Owens, Kalyn Shea, Ann J. Murkowski, Heather Price, and Anne M. Johansen. 2018. "A High-Throughput Model for CourseBased Research Experiences for the First Two Years of Chemistry and Biology.” In Hensel 2018a, 47-61.

Pascarella, Ernest T., Christopher T. Pierson, Gregory C. Wolniak, and Patrick T. Terenzini. 2004. "First-Generation College Students: Additional Evidence on College Experiences and Outcomes." Journal of Higher Education 75: 249-284. doi: 10.1353/jhe.2004.0016

Pratt, Clara C., William M. McGuigan, and Aphra R. Katzev. 2000. "Measuring Program Outcomes: Using Retrospective Pretest Methodology." American Journal of Evaluation 21: 341349. doi: 10.1016/S1098-2140(00)00089-8

Radunzel, Justine. 2018. "They May Be First but Will They Last? Retention and Transfer Behavior of First-Generation Students." Working Paper 2018-5. Iowa City: ACT.org. Accessed October 22, 2019. http://www.act.org/content/dam/act/unsecured/documents/R1708-retention-firstgen-2018-04.pdf

Rowland, Susan, Rhianna Pedwell, Gwen Lawrie, Joseph LovieToon, and Yu Hung. 2016. "Do We Need to Design CourseBased Undergraduate Research Experiences for Authenticity?" CBE-Life Sciences Education 15(4): ar79, 1-16. doi: 10.1187/ cbe.16-02-0102

Royles, Dan. 2016. "Teaching Digital Humanities with Oral History: The Staring Out to Sea Oral History Project and OHMS in the DH Classroom." Oral History Review 43: 408-420.

Smucker, Janneken, Doug Boyd, and Charles Hardy III. 2017. "Connecting the Classroom and the Archive: Oral History, Pedagogy, \& Goin' North." Oral History in the Digital Age. Washington, DC: Institute of Museum and Library Services. http://ohda.matrix.msu.edu/2017/02/connecting-the-classroomand-the-archive-oral-history-pedagogy-goin-north

University of Colorado Boulder. n.d. "Evaluation Tools: Undergraduate Research Self-Assessment (URSSA).” Ethnography and Evaluation Research, Research and Innovation Office. Accessed December 10, 2020. https://www.colorado.edu/eer/

34 Scholarship and Practice of Undergraduate Research research-areas/undergraduate-research/evaluation-tools-undergraduate-research-student-self

University of Kentucky. 2020. "Enrollment and Demographics." Institutional Research, Analytics and Decision Support. Accessed October 22, 2020. https://www.uky.edu/irads/enrollment-demographics

University of Kentucky. n.d. "Louie B. Nunn Center for Oral History: OHMS." University of Kentucky Libraries. Accessed December 10, 2020. http://libraries.uky.edu/libpage.php?lweb_ id=11\&llib_id $=13$

Wabash College. 2010. "Findings from the First Year of the Wabash National Study 2008-2009; Part I: Data Tables." University of Rhode Island data from Wabash National Study of Liberal Arts Education Accessed October 22, 2020. https://web.uri.edu/ assessment/files/2008-2009-Year-One-Data.pdf

Zhang, Daiyuan, Alexa Raney, and Robert J. Hatherill. 2018. "Student Outcomes in Discovery-Based Research." In Hensel 2018a, 167-182.

\section{Joshua R. McConnell Parsons}

University of Kentucky, joshua.parsons@uky.edu

Joshua R. McConnell Parsons serves as the associate director of the Evaluation Center in the University of Kentucky's College of Education. He earned a BA and MA in English literature as well as an EdM in education leadership and policy studies and is completing a doctorate in higher education at the University of Kentucky. His research is focused on class transitions within higher education and the relationship between high-impact academic practices and social and cultural capital.

Jannell C. McConnell Parsons is a PhD candidate in English and an instructor in the Writing, Rhetoric, and Digital Studies Department and in the English Department at the University of Kentucky. She served as a graduate student mentor to five graduate student instructors in academic year 2019-2020. She earned a BA in English and history, an MA in English, and an MFA in poetry. Her research is focused on American and transnational literatures, and writing and rhetoric pedagogies.

Kathryn Kohls is a PhD candidate in English and an instructor in the Writing, Rhetoric, and Digital Studies Department at the University of Kentucky. She currently serves as a graduate student mentor to five graduate student instructors for academic year 2020-2021. She earned a BA and an MA in English. Her research focus includes the remediation of nineteenth-century British literature and writing and rhetoric pedagogies.

Jim Ridolfo is an associate professor of writing, rhetoric, and digital studies, as well as director of composition, at the University of Kentucky. He earned a PhD from Michigan State University in rhetoric and writing, and his research focuses on the intersection of rhetorical theory and digital technology. 